This is the accepted version of the following article: Tang, L. and Lee, A. and Xu, F. and Zhang, T. and Lei, J. and Binns, C. 2014. Fruit and Vegetable Consumption and Risk of Esophageal Cancer: A Case-Control Study in North-West China. Diseases of the Esophagus. 27 (8): pp. 777-782, which has been published in final form at http://doi.org/10.1111/dote.12157 


\section{Fruit and vegetable consumption and risk of esophageal cancer: A case-control study in northwest China}

Li Tang ${ }^{1}$, Andy H Lee ${ }^{1}$, Fenglian Xu ${ }^{2}$, Taotao Zhang ${ }^{3}$, Jun Lei ${ }^{4}$, and Colin W Binns ${ }^{1}$

${ }^{1}$ School of Public Health, Curtin University, Perth, WA, Australia

${ }^{2}$ School of Women's and Children's Health, University of New South Wales, NSW, Australia

${ }^{3}$ School of Medicine, Shihezi University, Shihezi, Xinjiang, China

${ }^{4}$ Xinjiang Tumour Hospital, Urumqi, Xinjiang, China

Running title: Fruit, vegetable and esophageal cancer

Correspondence to: Professor Andy H. Lee, School of Public Health, Curtin University, GPO Box U 1987, Perth, WA, Australia, 6845. Email: Andy.Lee@curtin.edu.au, Tel: +61 8 9266 4180; Fax: +61892662958.

Authors' contributions: F.X. designed and co-ordinated the study, C.W.B. developed the study protocol, T.Z. and J.L. recruited participants and undertook data collection, L.T. and A.H.L conducted data analysis and interpreted the data, L.T. drafted the manuscript. All authors have reviewed and approved the manuscript. 


\section{ABSTRACT}

The north-western region of China carries a big burden of esophageal cancer with incidence above the national average. This study ascertained the association between fruit and vegetable consumption and the risk of esophageal cancer in this remote part of China. A case-control study was undertaken in Urumqi and Shihezi, Xinjiang Uyghur Autonomous Region of China, between 2008 and 2009. Participants were 359 incident esophageal cancer patients and 380 hospital-based controls. Information on habitual fruit and vegetable consumption was obtained by face-to-face interview using a validated semi-quantitative food frequency questionnaire. Unconditional logistic regression analyses were performed to assess the strength of the associations. The esophageal cancer patients consumed significantly less fruits (mean 364.3, SD $497.4 \mathrm{~g}$ ) and vegetables (mean 711.4, SD $727.9 \mathrm{~g}$ ) daily than their counterparts without the disease (mean 496.5, SD $634.4 \mathrm{~g}$ and mean 894.5, SD $746.1 \mathrm{~g}$, respectively). The adjusted odds ratios were 0.48 (95\% confidence interval 0.33 to 0.71$)$ and 0.46 (95\% confidence interval 0.32 to 0.68$)$ for consuming at least $515 \mathrm{~g}$ of fruits and $940 \mathrm{~g}$ of vegetables per day, respectively, relative to at most $170 \mathrm{~g}$ and $520 \mathrm{~g}$. With respect to nutrients contained in fruits and vegetables, intakes of vitamin $\mathrm{C}$, vitamin E, $\beta$-cryptoxanthin, potassium and magnesium at high levels also reduced the esophageal cancer risk. In conclusion, inverse associations were evident between consumption of fruits and vegetables and the risk of esophageal cancer for adults residing in northwest China.

Keywords: fruit, vegetable, nutrients, esophageal cancer, China 


\section{INTRODUCTION}

Esophageal cancer is the eighth most common malignancy and the sixth leading cause of cancer-related deaths worldwide. In 2008, more than 480,000 new cases of esophageal cancer and approximately 407,000 related deaths were reported. ${ }^{1}$ Esophageal cancer is typically diagnosed at an advanced stage. It has a poor prognosis with five-year survival rate less than $20 \%{ }^{2}$ Therefore, primary prevention of this major disease of the esophagus is important.

Fruits and vegetables are rich in anticancer agents, such as vitamins, folate, carotenoids and certain minerals. ${ }^{3}$ Previous studies have generally demonstrated fruits and vegetables can inhibit the development of esophageal cancer, ${ }^{4-6}$ but the findings remained inconsistent. ${ }^{78}$ Similarly, conflicting results have been reported in the Chinese population, especially with respect to vegetable consumption. A recent case-control study, conducted in Shanxi Province of north-central China, attributed the observed reduced risk of esophageal cancer to regular intake of fruits and vegetables. ${ }^{9}$ However, a prospective cohort study in Shanghai found little association between the esophageal cancer risk and vegetable consumption, which could be due to the loss of protective components during high-heat stir-frying. ${ }^{10}$

Xinjiang Uyghur Autonomous Region, located in the northwest of China, is one of the areas constituting the so-called 'Asian Esophageal Cancer Belt'. ${ }^{11}$ According to a survey conducted in Xinjiang between 2005 and 2008, the incidence of esophageal cancer was 
30.2 per 100,000 , much higher than the national average during the same period. ${ }^{12}$ In view of the conflicting epidemiological evidence, the present study aimed to ascertain the association between fruit and vegetable consumption and the risk of esophageal cancer among adults residing in this remote region of China.

\section{MATERIALS AND METHODS}

\section{Study design and participants}

A hospital-based case-control study of esophageal cancer was conducted in Urumqi and Shihezi, Xinjiang Uyghur Autonomous Region of China, between January 2008 and December 2009. Participants were recruited from the Xinjiang Tumour Hospital, Shihezi People's Hospital, Kuitong Hospital and No. 1 Affiliated Hospital of Shihezi University. Medical records and pathology reports were checked to identify newly diagnosed patients (within the past 12 months). Pathological diagnoses were based on the World Health Organization's Classification of Tumours of the Digestive System. ${ }^{13}$ Patients without histopathological confirmation were excluded. Of the total 364 incident patients identified, 359 consented to participate.

Meanwhile, controls were recruited among inpatients at the same hospitals from the departments of Ophthalmology, Orthopaedic, Respiratory Disease and Physiotherapy. Exclusion criteria for controls were previous diagnosis of any malignant disease, on longterm medical diet, and self-reported memory problems assessed by asking whether they 
could recall previous day events. Whenever more controls were available than could be interviewed, the final selection was made using random numbers. Of the 400 eligible controls recruited to frequency matched with cases by gender and age (within 5 years), 380 eventually gave their consent to be interviewed (response rate 95\%). There were no significant differences in age, gender and demographics between participants and nonparticipants in both case and control groups.

The study protocol was approved by the participating hospitals and the Human Research Ethics Committee of Curtin University (approval number HR 56/2006), and conformed to the provisions of the Declaration of Helsinki. Written informed consent was obtained from all participants, who were assured of confidentiality of the information provided and their right to withdraw at any time without prejudice

\section{Data collection}

All participants were interviewed face-to-face by trained nursing staff, usually in the presence of their next-of-kin to help the recall of past events. A structured questionnaire was administered to collect information on demographic characteristics, anthropometry, past and family medical history, as well as lifestyle such as cigarette smoking and alcohol drinking. Information on diet was solicited using a validated 137-item semi-quantitative food frequency questionnaire, which included commonly consumed fruits and vegetables in northwest China. Frequency and amount of intake were recorded in detail. The reference 
recall period for dietary variables was set at five years before diagnosis for cases and five years before interview for controls. The energy content of each food or beverage item was obtained from the Chinese Food Composition Tables. ${ }^{14}$ We then estimated each participant's total energy intake (kcal/day) by summing the energy content across individual items consumed.

Total vegetable intake was defined as the sum of daily consumption of green leafy vegetables (spinach, lettuce, celtuce leaf, pea shoot), cruciferous vegetables (broccoli, cole, cabbage, Chinese cabbage, cauliflower, white radish), yellow orange vegetables (tomato, carrot, sweat potatoes, red chilli), allium vegetables (leek, onion, scallion, garlic bolt, garlic) and other vegetables (celery, eggplant, cucumber, zucchini, lotus root, potato, Chinese yam, lentil, snow pea, snap bean, long bean, mung bean sprout, green capsicum, celtuce stem, bitter gourd, wax gourd, bamboo shoot). Preserved (salted/pickled) vegetables, typically consumed in small amounts, were excluded in the total fresh vegetable intake. Total fruit intake was defined as the sum of daily consumption of yellow orange fruits (banana, orange, peach, persimmon, watermelon, strawberry, pineapple, hawthorn fruit, fresh date) and other fruits (apple, pear, grape, dew melon).

\section{Statistical analysis}

Descriptive statistics were used to summarize the sample characteristics. Unconditional logistic regression analyses were performed to assess the effects of fruit and vegetable 
consumption on the esophageal cancer risk. Both crude and adjusted odds ratios (OR) and corresponding 95\% confidence intervals (CI) were computed.

The main nutrients contained in fruits and vegetables, except carotenoids, were identified and estimated using the Chinese Food Composition Tables. ${ }^{14}$ The nutrient database of the USA Department of Agriculture ${ }^{15}$ was used for the calculation of carotenoids. Effects of the selected nutrients were then ascertained by separate logistic regression models.

For each exposure variable of interest, the categorical cutoff points were derived from the tertiles of consumption corresponding to the control distribution, with the lowest level being the reference category. Confounding variables included in the logistic regression models were age (years), gender, education level (none/primary, secondary, tertiary), body mass index (5 years ago, $\left.\mathrm{kg} / \mathrm{m}^{2}\right)$, total energy intake ( $\mathrm{kcal} /$ day), smoking status (never, ever), alcohol drinking (never/seldom, often) and family history of cancer in first-degree relatives (no, yes). These variables were either established or plausible risk factors of esophageal cancer from the literature. All statistical analyses were undertaken using the SPSS package version 20.

\section{RESULTS}

Table 1 presents characteristics of the sample by case-control status. The participants were on average 61 (SD 11.4) years old with mean body mass index 24.1 (SD 3.7) $\mathrm{kg} / \mathrm{m}^{2}$. The 
majority (72\%) of them were male. Approximately half the participants were smokers and regularly drank alcoholic beverages. Compared to the controls, patients with esophageal cancer tended to belong to the ethnic minority group $(\mathrm{p}=0.001)$, have lower education level $(\mathrm{p}<0.001)$ but a family history of esophageal cancer $(\mathrm{p}<0.001)$.

Table 2 compares the mean daily consumptions of fruits and vegetables between case and control groups. Patients with esophageal cancer consumed significantly less total fruits (mean 364.3, SD $497.4 \mathrm{~g}$ ) and total vegetables (mean 711.4, SD $727.9 \mathrm{~g}$ ) per day than adults without the disease (mean 496.5, SD $634.4 \mathrm{~g}$ and mean 894.5, SD $746.1 \mathrm{~g}$, respectively), according to both $\mathrm{t}$ tests and Mann-Whitney tests. Table 3 shows the daily intake of selected nutrients derived from fruits and vegetables. Compared to controls, the esophageal cancer patients reported significantly lower intakes of vitamin C, vitamin E, niacin, folate, $\beta$-cryptoxanthin, potassium, magnesium and calcium. Further subgroup analysis by ethnicity (Han versus Uyghur minority people) produced similar results which were omitted for brevity.

Table 4 gives the results of logistic regression analyses for fruit, vegetable and their subgroups. Over 50\% reductions in esophageal cancer risk were observed for the highest levels of total fruit and total vegetable intake; the adjusted OR being 0.48 (95\% CI 0.33 to 0.71 ) and 0.46 (95\% CI 0.32 to 0.68 ) for consuming at least $515 \mathrm{~g}$ of fruit and $940 \mathrm{~g}$ of vegetable, respectively, relative to at most $170 \mathrm{~g}$ and $520 \mathrm{~g}$. With the exception of green 
leafy vegetable, increased consumption at each subgroup was apparently associated with a reduced risk of esophageal cancer.

Finally, Table 5 summarises the logistic regression results for selected nutrients contained in fruits and vegetables. Inverse associations were found between the incidence of esophageal cancer and intakes of Vitamin C, Vitamin E, $\beta$-cryptoxanthin, potassium and magnesium, together with significant dose-response relationships (results omitted for brevity).

\section{DISCUSSION}

This case-control study in north-western China suggested a protective role for fruits vegetables against esophageal cancer development, with supportive evidence from the corresponding dietary nutrients. Compared with previous research for the Chinese population, our findings are consistent with a hospital-based case-control study in Shanxi

Province ${ }^{9}$ and two other case-control studies conducted in Taiwan, ${ }^{16,17}$ though somewhat different from a prospective cohort study undertaken in Shanghai, which found little association between vegetable intake and the esophageal cancer risk. ${ }^{10}$

Besides total fruit and total vegetable, the consumptions of most subgroups were shown to be similarly beneficial in the present study, suggesting that many components or nutrients contained in fruits and vegetables might be responsible for their preventive effect. Vitamin $\mathrm{C}$ and vitamin $\mathrm{E}$, acting as scavengers of reactive oxygen species, may protect 
esophageal cells against oxidative damage and DNA destruction. ${ }^{18}$ Moreover, vitamin C is important in impeding the endogenous synthesis of $\mathrm{N}$-nitroso compounds, which are potential carcinogens for the esophagus. ${ }^{19}$ In addition, carotenoids from fruits and vegetables have been implicated in cancer prevention because of their strong antioxidant activity, inhibition of proliferation and induction of detoxifying enzymes. ${ }^{20}$

Similar to a previous study in the USA, ${ }^{21}$ among the carotenoids considered, only $\beta$ cryptoxanthin emerged to exhibit an inverse association with esophageal cancer. On the other hand, both magnesium and potassium are essential minerals for normal cellular function. Dietary magnesium may inhibit carcinogenesis due to its stabilizing effect on DNA and regulatory role in cell cycle control and apoptosis, ${ }^{22}$ whereas experimental studies are needed to understand the biological mechanism concerning the anticancer properties of potassium.

In this study, a standardised identification procedure had been implemented that ensured the ascertainment of cases was maximised and complete. To avoid misclassification of the case-control status, only incident patients were recruited, who had been diagnosed with esophageal cancer within the past 12 months and subsequently confirmed with pathology. All controls were carefully screened. Dietary intake was measured using a validated food frequency questionnaire, with information on frequency and quantity of intake recorded in detail. To determine the effect of fruit and vegetable consumption, information on other exposures and confounding factors such as tobacco 
smoking, alcohol drinking and family history of cancer was also collected. It was possible that some esophageal cancer patients might have modified their dietary behaviours since the onset of the disease. Therefore, the reference period for habitual fruit and vegetable consumption was set at five years ago to avoid reverse causation.

Several biases and limitations should be taken into consideration. A major limitation concerns the retrospective cross-sectional nature of the case-control design so that a causeeffect relationship between fruit and vegetable consumption and esophageal cancer risk could not be established. Nevertheless, the use of four hospitals reduced sampling bias, and as they serve the entire catchment region, our participants could be considered as representative of the target population of Xinjiang Province. Although the recall of habitual food consumption should not be affected by the case-control status, dietary assessment was made based on self-report, which probably introduced some recall error in the response of participants. Face-to-face interviews were thus conducted in the presence of next-of-kin to help improve the accuracy of their answers. Furthermore, information bias and recall bias were unlikely because all participants were blind to the study hypothesis. Finally, using proxy values from the USDA nutrients database might lead to underestimation of certain carotenoid intakes, since several common fruits and vegetables in northwest China were not covered by the database. Nevertheless, it should not bias the results because the same estimation procedure was consistently applied to both case and control groups. 
In conclusion, habitual consumption of fruits and vegetables appeared to be inversely associated with the risk of esophageal cancer for adults in northwest China, together with supportive evidence from the corresponding dietary nutrients. While population-based prospective cohort studies are required to confirm the effect of long term consumption, it is still appropriate to recommend consuming a wide variety of fruits and vegetables for the prevention of this major disease.

\section{ACKNOWLEDGEMENTS}

Thanks are due to the esophageal cancer patents and control participants who agreed to be interviewed, and to the medical and nursing staff of the participating hospitals for their assistance in recruitment. This research received no specific grant from any funding agency, commercial or not-for-profit organisations. There are no conflicts of interest for all authors. 


\section{REFERENCES}

1. Ferlay J, Shin H, Bray F, Forman D, Mathers C, Parkin D. Cancer incidence and mortality worldwide. Lyon: International Agency for Research on Cancer; 2010 [cited 25 Jun 2013]. Available from: http://globocan.iarc.fr

2. Palladino-Davis AG, Mendez BM, Fisichella PM, Davis CS. Dietary habits and esophageal cancer. Dis Esophagus 2013; doi:10.1111/dote.12097 (Epublication ahead of print version).

3. Hunt JR. Bioavailability of iron, zinc, and other trace minerals from vegetarian diets. Am J Clin Nutr 2003; 78: 633S-9S.

4. Navarro Silvera SA, Mayne ST, Risch H et al. Food group intake and risk of subtypes of esophageal and gastric cancer. Int J Cancer 2008; 123: 852-60.

5. Veugelers PJ, Porter GA, Guernsey DL, Casson AG. Obesity and lifestyle risk factors for gastroesophageal reflux disease, Barrett esophagus and esophageal adenocarcinoma. Dis Esophagus 2006; 19: 321-8.

6. Jeurnink SM, Buchner FL, Bueno-de-Mesquita HB et al. Variety in vegetable and fruit consumption and the risk of gastric and esophageal cancer in the European Prospective Investigation into Cancer and Nutrition. Int J Cancer 2012; 131: E96373.

7. De Ceglie A, Fisher DA, Filiberti R, Blanchi S, Conio M. Barrett's esophagus, esophageal and esophagogastric junction adenocarcinomas: the role of diet. Clin Res Hepatol Gastroenterol 2011; 35: 7-16. 
8. Gonzalez CA, Pera G, Agudo A et al. Fruit and vegetable intake and the risk of stomach and oesophagus adenocarcinoma in the European Prospective Investigation into Cancer and Nutrition (EPIC-EURGAST). Int J Cancer 2006; 118: 2559-66.

9. Gao Y, Hu N, Han XY et al. Risk factors for esophageal and gastric cancers in Shanxi Province, China: a case-control study. Cancer Epidemiol 2011; 35: e91-9.

10. Fan Y, Yuan JM, Wang R, Gao YT, Yu MC. Alcohol, tobacco, and diet in relation to esophageal cancer: the Shanghai Cohort Study. Nutr Cancer 2008; 60: 354-63.

11. Mao WM, Zheng WH, Ling ZQ. Epidemiologic risk factors for esophageal cancer development. Asian Pac J Cancer Prev 2011; 12: 2461-6.

12. Ainiwaer J, Li D, Zhang L, Xiaheding Y, Tuerxunnayi, Liu Y. [A survey of oesophageal cancer incidence in Yili, Xinjiang between 2005 and 2008]. Xinjiang Medical Journal 2011; 41: 112-4. [in Chinese].

13. Garbbert HE, Shimoda T, Hainaut P, Nakamura Y, Field JK, Inoue H. Tumours of the Oesophagus. In: Hamilton SR, Aaltonen LA (eds) World Health Organization Classification of Tumours Pathology and Genetics of Tumours of the Digestive System. Lyon: IARC Press, 2000; 9-30.

14. Chinese Center for Disease Control and Prevention. China Food Composition Table, 2nd edn. Beijing: Peking University Medical Press, 2009. 
15. U.S. Department of Agriculture, Agricultural Research Service. 2012. USDA National Nutrient Database for Standard Reference, Release 25. [cited 2 Jul 2013] Available from: http://www.ars.usda.gov/ba/bhnrc/ndl.

16. Chen $\mathrm{YK}$, Lee $\mathrm{CH}$, Wu IC et al. Food intake and the occurrence of squamous cell carcinoma in different sections of the esophagus in Taiwanese men. Nutrition 2009; 25: 753-61.

17. Hung HC, Huang MC, Lee JM, Wu DC, Hsu HK, Wu MT. Association between diet and esophageal cancer in Taiwan. J Gastroenterol Hepatol 2004; 19: 632-7.

18. Lukic M, Segec A, Segec I et al. The impact of the vitamins A, C and E in the prevention of gastroesophageal reflux disease, Barrett's oesophagus and oesophageal adenocarcinoma. Coll Antropol 2012; 36: 867-72.

19. Keszei AP, Goldbohm RA, Schouten LJ, Jakszyn P, van den Brandt PA. Dietary N-nitroso compounds, endogenous nitrosation, and the risk of esophageal and gastric cancer subtypes in the Netherlands Cohort Study. Am J Clin Nutr 2013; 97 : $135-46$.

20. Smith TA. Carotenoids and cancer: prevention and potential therapy. Br J Biomed Sci 1998; 55: 268-75.

21. Chen H, Tucker KL, Graubard BI et al. Nutrient intakes and adenocarcinoma of the esophagus and distal stomach. Nutr Cancer 2002; 42: 33-40.

22. Hartwig A. Role of magnesium in genomic stability. Mutat Res 2001; 475: 113-21. 
Table 1. Characteristics of participants by case-control status in northwest China

\begin{tabular}{|c|c|c|c|}
\hline Variable & Cases & Controls & $\mathbf{p}^{\dagger}$ \\
\hline & $\mathrm{n}(\%)$ & $\mathrm{n}(\%)$ & \\
\hline Gender & & & 0.623 \\
\hline Male & $260(72.4 \%)$ & $269(70.8 \%)$ & \\
\hline Female & $99(27.6 \%)$ & $111(29.2 \%)$ & \\
\hline Ethnic group & & & 0.001 \\
\hline Han & $270(75.2 \%)$ & $322(84.7 \%)$ & \\
\hline Minority & $89(24.8 \%)$ & $58(15.3 \%)$ & \\
\hline Education level & & & $<0.001$ \\
\hline None/primary & $183(51.0 \%)$ & $136(35.8 \%)$ & \\
\hline Secondary & $140(39.0 \%)$ & $191(50.3 \%)$ & \\
\hline Tertiary & $36(10.0 \%)$ & $53(13.9 \%)$ & \\
\hline Smoking status & & & 0.188 \\
\hline Never & $164(45.7 \%)$ & $192(50.5 \%)$ & \\
\hline Ever & $195(54.3 \%)$ & $188(49.5 \%)$ & \\
\hline Alcohol drinking & & & 0.216 \\
\hline Never/seldom & $193(53.8 \%)$ & $187(49.2 \%)$ & \\
\hline Often & $166(46.2 \%)$ & $193(50.8 \%)$ & \\
\hline
\end{tabular}


Family history of cancer in first-degree

relatives

No

Yes

Age at interview (years) $\ddagger$

Body mass index $\left(5\right.$ years ago, $\left.\mathrm{kg} / \mathrm{m}^{2}\right) \ddagger$

Total energy intake (kcal/day)
$306(85.2 \%) \quad 356(93.7 \%)$

$53(14.8 \%) \quad 24(6.3 \%)$

$61.4(11.0) \quad 60.6(11.8) \quad 0.338$

$24.3(3.8) \quad 24.0(3.6) \quad 0.181$

$4310(2681) \quad 4709(2716) \quad 0.047$

$\uparrow$ Chi-square or t-test for difference between cases and controls

t Mean (SD) 
Table 2. Comparison of fruit and vegetable consumption between case and control groups in northwest China

\begin{tabular}{lccc}
\hline Daily intake (g) & Cases & Controls & p $\dagger$ \\
& Mean (SD) & Mean (SD) & \\
\hline Total vegetables & $711.4(727.9)$ & $894.5(746.1)$ & 0.001 \\
Green leafy vegetables & $52.6(81.1)$ & $66.6(107.2)$ & 0.045 \\
Cruciferous vegetables & $127.5(137.2)$ & $173.1(155.1)$ & $<0.001$ \\
Yellow orange vegetables & $138.0(179.0)$ & $160.5(223.2)$ & 0.133 \\
Allium vegetables & $92.2(125.5)$ & $103.5(126.0)$ & 0.222 \\
Other vegetables & $301.0(394.3)$ & $390.8(381.6)$ & 0.002 \\
Total fruits & $364.3(497.4)$ & $496.5(634.4)$ & 0.002 \\
Yellow orange fruits & $206.0(336.4)$ & $279.6(373.1)$ & 0.005 \\
Other fruits & $158.2(212.9)$ & $216.9(303.9)$ & 0.002 \\
\hline
\end{tabular}

$\dagger$ t-test for mean difference between cases and controls 
Table 3. Comparison of selected nutrients intake between case and control groups in northwest China

\begin{tabular}{|c|c|c|c|}
\hline Daily intake & Cases & Controls & $\mathbf{p}^{\dagger}$ \\
\hline & Mean (SD) & Mean (SD) & \\
\hline Vitamin C (mg) & $246.44(270.73)$ & $307.63(269.58)$ & 0.002 \\
\hline Vitamin E (mg) & $7.53(7.38)$ & $9.41(8.05)$ & 0.001 \\
\hline Niacin (mg) & $8.65(10.05)$ & $10.45(13.13)$ & 0.037 \\
\hline Folate $(\mu \mathrm{g})$ & $193.98(217.69)$ & $229.65(245.90)$ & 0.037 \\
\hline$\alpha$-carotene $(\mu \mathrm{g})$ & $1231.88(2168.69)$ & 1270.55 (2063.44) & 0.804 \\
\hline$\beta$-carotene $(\mu \mathrm{g})$ & $8555.94(8826.91)$ & 9708.97 (9600.59) & 0.089 \\
\hline$\beta$-cryptoxanthin $(\mu \mathrm{g})$ & $151.05(234.22)$ & $198.39(255.85)$ & 0.009 \\
\hline Lutein + zeaxanthin $(\mu \mathrm{g})$ & $5532.47(7801.07)$ & $6023.88(8642.76)$ & 0.418 \\
\hline Lycopene $(\mu \mathrm{g})$ & $2958.95(4923.37)$ & $3690.19(7226.65)$ & 0.110 \\
\hline Potassium (mg) & $1561.87(1458.18)$ & $1962.73(1729.65)$ & 0.001 \\
\hline Magnesium (mg) & $178.01(180.09)$ & $218.14(189.43)$ & 0.003 \\
\hline Calcium (mg) & $374.87(391.32)$ & $438.40(396.63)$ & 0.029 \\
\hline Iron (mg) & $10.40(12.94)$ & $11.76(10.76)$ & 0.119 \\
\hline
\end{tabular}

$\dagger \mathrm{t}$-test for mean difference between cases and controls 
Table 4. Crude and adjusted odds ratio (95\% confidence interval) of esophageal cancer risk for fruit and vegetable consumption among adults in northwest China

\begin{tabular}{|c|c|c|c|c|c|}
\hline $\begin{array}{l}\text { Daily } \\
\text { intake (g) }\end{array}$ & $\begin{array}{l}\text { Cases } \\
\mathrm{n}(\%)\end{array}$ & $\begin{array}{c}\text { Controls } \\
\text { n }(\%)\end{array}$ & $\begin{array}{c}\text { Crude OR } \\
(95 \% \mathrm{CI})\end{array}$ & $\begin{array}{c}\text { Adjusted OR } \\
\dagger \\
(95 \% \mathrm{CI})\end{array}$ & $\mathbf{p}^{\dagger}$ \\
\hline $\begin{array}{l}\text { Total } \\
\text { vegetables }\end{array}$ & & & & & $<0.001$ \\
\hline$<520$ & $\begin{array}{c}190 \\
(52.9 \%)\end{array}$ & $\begin{array}{c}127 \\
(33.4 \%)\end{array}$ & 1.00 & 1.00 & \\
\hline $520-940$ & $\begin{array}{c}89 \\
(24.8 \%)\end{array}$ & $\begin{array}{c}129 \\
(33.9 \%)\end{array}$ & $\begin{array}{c}0.46 \\
(0.33,0.66)\end{array}$ & $\begin{array}{c}0.49 \\
(0.34,0.70)\end{array}$ & \\
\hline$>940$ & $\begin{array}{c}80 \\
(22.3 \%)\end{array}$ & $\begin{array}{c}124 \\
(32.6 \%)\end{array}$ & $\begin{array}{c}0.43 \\
(0.30,0.62)\end{array}$ & $\begin{array}{c}0.46 \\
(0.32,0.68)\end{array}$ & \\
\hline $\begin{array}{l}\text { Green leafy } \\
\text { vegetables }\end{array}$ & & & & & 0.997 \\
\hline$<14$ & $\begin{array}{c}119 \\
(33.1 \%)\end{array}$ & $\begin{array}{c}127 \\
(33.4 \%)\end{array}$ & 1.00 & 1.00 & \\
\hline $14-50$ & $\begin{array}{c}126 \\
(35.1 \%)\end{array}$ & $\begin{array}{c}128 \\
(33.7 \%)\end{array}$ & $\begin{array}{c}1.05 \\
(0.74,1.49)\end{array}$ & $\begin{array}{c}0.99 \\
(0.69,1.42)\end{array}$ & \\
\hline
\end{tabular}




\begin{tabular}{ccccc}
\hline$>50$ & 114 & 125 & 0.97 & 1.00 \\
& $(31.8 \%)$ & $(32.9 \%)$ & $(0.68,1.39)$ & $(0.69,1.45)$
\end{tabular}

Cruciferous

$<0.001$

vegetables

$\begin{array}{lllll}<81 & 163 & 129 & 1.00 & 1.00\end{array}$

$(45.4 \%) \quad(33.9 \%)$

$\begin{array}{lllll}81-200 & 133 & 128 & 0.82 & 0.84\end{array}$

$(37.0 \%) \quad(33.7 \%) \quad(0.59,1.15) \quad(0.59,1.19)$

$>200$

63

123

0.41

0.43

$\begin{array}{llll}(17.5 \%) & (32.4 \%) & (0.28,0.59) & (0.29,0.64)\end{array}$

Yellow orange

0.038

vegetables

$<62$

127

130

1.00

1.00

$(35.4 \%) \quad(34.2 \%)$

$62-155$

142

124

1.17

1.22

$(39.6 \%) \quad(32.6 \%) \quad(0.83,1.65) \quad(0.86,1.74)$

$>155$

90

126

0.73

0.74

$(25.1 \%) \quad(33.2 \%) \quad(0.51,1.05) \quad(0.50,1.09)$

Allium

0.015

vegetables 


\begin{tabular}{|c|c|c|c|c|c|}
\hline \multirow[t]{2}{*}{$<35$} & 123 & 132 & 1.00 & 1.00 & \\
\hline & $(34.3 \%)$ & $(34.7 \%)$ & & & \\
\hline \multirow[t]{2}{*}{$35-111$} & 153 & 123 & 1.34 & 1.26 & \\
\hline & $(42.6 \%)$ & $(32.4 \%)$ & $(0.95,1.88)$ & $(0.89,1.80)$ & \\
\hline \multirow[t]{2}{*}{$>111$} & 83 & 125 & 0.71 & 0.72 & \\
\hline & $(23.1 \%)$ & $(32.9 \%)$ & $(0.49,1.03)$ & $(0.49,1.07)$ & \\
\hline Other & & & & & $<0.001$ \\
\hline \multicolumn{6}{|l|}{ vegetables } \\
\hline \multirow[t]{2}{*}{$<205$} & 190 & 127 & 1.00 & 1.00 & \\
\hline & $(52.9 \%)$ & $(33.4 \%)$ & & & \\
\hline \multirow[t]{2}{*}{$205-420$} & 96 & 128 & 0.50 & 0.54 & \\
\hline & $(26.7 \%)$ & $(33.7 \%)$ & $(0.35,0.71)$ & $(0.38,0.78)$ & \\
\hline \multirow[t]{2}{*}{$>420$} & 73 & 125 & 0.39 & 0.40 & \\
\hline & $(20.3 \%)$ & $(32.9 \%)$ & $(0.27,0.56)$ & $(0.27,0.59)$ & \\
\hline Total fruits & & & & & 0.001 \\
\hline \multirow[t]{2}{*}{$<170$} & 168 & 126 & 1.00 & 1.00 & \\
\hline & $(46.8 \%)$ & $(33.2 \%)$ & & & \\
\hline \multirow[t]{2}{*}{$170-515$} & 116 & 131 & 0.66 & 0.71 & \\
\hline & $(32.3 \%)$ & $(34.5 \%)$ & $(0.47,0.93)$ & $(0.50,1.02)$ & \\
\hline \multirow[t]{2}{*}{$>515$} & 75 & 123 & 0.46 & 0.48 & \\
\hline & $(20.9 \%)$ & $(32.4 \%)$ & $(0.32,0.66)$ & $(0.33,0.71)$ & \\
\hline
\end{tabular}


Yellow orange

fruits

$<90$

178

128

1.00

1.00

$(49.6 \%) \quad(33.7 \%)$

$90-272$

104

127

0.59

0.59

$(29.0 \%)$

$(33.4 \%)$

$(0.42,0.83)$

$(0.41,0.85)$

$>272$

77

125

0.44

0.47

$(21.4 \%) \quad(32.9 \%) \quad(0.31,0.64) \quad(0.32,0.69)$

Other fruits

$<66$

156

127

1.00

1.00

$(43.5 \%) \quad(33.4 \%)$

$66-207$

121

126

0.78

0.84

$(33.7 \%)$

$(33.2 \%)$

$(0.56,1.10)$

$(0.59,1.19)$

$>207$

82

127

0.53

0.57

$(22.8 \%)$

$(33.4 \%)$

$(0.37,0.76)$

$(0.39,0.84)$

$<0.001$

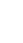


Table 5. Crude and adjusted odds ratio (95\% confidence interval) of esophageal cancer risk for intake of selected nutrients among adults in northwest China

\begin{tabular}{|c|c|c|c|c|c|}
\hline Daily intake & Cases & Controls & Crude OR & Adjusted $\mathrm{OR} \dagger$ & $\mathbf{p}^{\dagger}$ \\
\hline & $\mathrm{n}(\%)$ & $\mathrm{n}(\%)$ & $(95 \% \mathrm{CI})$ & $(95 \% \mathrm{CI})$ & \\
\hline Vitamin C (mg) & & & & & 0.001 \\
\hline \multirow[t]{2}{*}{$<168.0$} & 174 & 126 & 1.00 & 1.00 & \\
\hline & $(48.5 \%)$ & $(33.2 \%)$ & & & \\
\hline \multirow[t]{2}{*}{$168.0-310.0$} & 100 & 127 & 0.57 & 0.58 & \\
\hline & $(27.8 \%)$ & $(33.4 \%)$ & $(0.40,0.81)$ & $(0.41,0.83)$ & \\
\hline \multirow[t]{2}{*}{$>310.0$} & 85 & 127 & 0.49 & 0.54 & \\
\hline & $(23.7 \%)$ & $(33.4 \%)$ & $(0.34,0.69)$ & $(0.37,0.79)$ & \\
\hline Vitamin E (mg) & & & & & 0.010 \\
\hline \multirow[t]{2}{*}{$<5.3$} & 171 & 129 & 1.00 & 1.00 & \\
\hline & $(47.6 \%)$ & $(34.0 \%)$ & & & \\
\hline \multirow[t]{2}{*}{$5.3-9.8$} & 103 & 124 & 0.63 & 0.66 & \\
\hline & $(28.7 \%)$ & $(32.6 \%)$ & $(0.44,0.89)$ & $(0.46,0.94)$ & \\
\hline \multirow[t]{2}{*}{$>9.8$} & 85 & 127 & 0.51 & 0.58 & \\
\hline & $(23.7 \%)$ & $(33.4 \%)$ & $(0.35,0.72)$ & $(0.40,0.85)$ & \\
\hline
\end{tabular}

Niacin $(m g)$

0.110 


$\begin{array}{lcccc}<4.7 & 158 & 130 & 1.00 & 1.00 \\ & (44.0 \%) & (34.2 \%) & & \\ 4.7-9.9 & 104 & 123 & 0.70 & 0.73 \\ & (29.0 \%) & (32.4 \%) & (0.49,0.99) & (0.51,1.05) \\ & & & & \\ & 9.9 & 127 & 0.63 & 0.70 \\ & (27.0 \%) & (33.4 \%) & (0.44,0.89) & (0.48,1.03)\end{array}$

Folate $(\mu \mathrm{g})$

0.302

$<104.5$

142

127

1.00

1.00

$(39.6 \%) \quad(33.4 \%)$

$104.5-204.5$

108

126

0.77

0.75

$(30.1 \%) \quad(33.2 \%) \quad(0.54,1.09) \quad(0.52,1.08)$

$>204.5$

109

127

0.77

0.87

$(30.4 \%) \quad(33.4 \%) \quad(0.54,1.09) \quad(0.60,1.27)$

$\alpha$-carotene $(\mu \mathrm{g})$

0.623

$<270.0$

126

127

1.00

1.00

$(35.1 \%) \quad(33.4 \%)$

$270.0-1114.0$

127

126

1.02

1.02

$(35.4 \%) \quad(33.2 \%) \quad(0.72,1.44) \quad(0.71,1.46)$

$>1114.0$

106

127

0.84

0.86

$(29.5 \%) \quad(33.4 \%) \quad(0.59,1.20) \quad(0.59,1.25)$

$\beta$-carotene $(\mu \mathrm{g})$

0.944 


\begin{tabular}{|c|c|c|c|c|}
\hline \multirow[t]{2}{*}{$<4530.0$} & 124 & 127 & 1.00 & 1.00 \\
\hline & $(34.5 \%)$ & $(33.4 \%)$ & & \\
\hline \multirow[t]{2}{*}{$4530.0-9800.0$} & 129 & 126 & 1.05 & 1.02 \\
\hline & $(35.9 \%)$ & $(33.2 \%)$ & $(0.74,1.49)$ & $(0.71,1.47)$ \\
\hline \multirow[t]{2}{*}{$>9800.0$} & 106 & 127 & 0.86 & 0.96 \\
\hline & $(29.5 \%)$ & $(33.4 \%)$ & $(0.60,1.22)$ & $(0.65,1.40)$ \\
\hline
\end{tabular}

$\beta$-cryptoxanthin

$(\mu g)$

$<65.0$

170

128

1.00

1.00

$(47.4 \%) \quad(33.7 \%)$

$65.0-180.0$

106

125

0.64

0.64

$(29.5 \%) \quad(32.9 \%) \quad(0.45,0.90) \quad(0.45,0.92)$

$>180.0$

83

127

0.49

0.54

$(23.1 \%) \quad(33.4 \%) \quad(0.34,0.71) \quad(0.37,0.79)$

Lutein +

zeaxanthin $(\mu \mathrm{g})$

$<2174.0$

133

128

1.00

1.00

$(37.0 \%) \quad(33.7 \%)$

$2174.0-4965.0$

99

126

0.76

0.71

$(27.6 \%) \quad(33.2 \%) \quad(0.53,1.08) \quad(0.49,1.03)$ 


$$
>4965.0
$$

127

$$
126
$$

0.97

1.06

$$
(35.4 \%) \quad(33.2 \%) \quad(0.69,1.37) \quad(0.74,1.53)
$$

Lycopene $(\mu \mathrm{g})$

$$
<1100.00
$$$$
144
$$$$
124
$$$$
1.00
$$$$
1.00
$$

$$
(40.4 \%) \quad(32.9 \%)
$$

$1100.0-3280.0$

111

123

0.78

0.75

$$
(31.2 \%) \quad(32.6 \%) \quad(0.55,1.10) \quad(0.52,1.08)
$$

> 3280.0

$$
101
$$

130

0.67

0.67

$(28.4 \%)$

$(34.5 \%)$

$(0.47,0.95)$

$(0.46,0.97)$

Potassium (mg)

$$
<1200.0
$$

195

147

1.00

1.00

$$
(54.3 \%) \quad(38.7 \%)
$$

$1200.0-2290.0$

91

119

0.58

0.58

$(25.3 \%)$

$$
(31.3 \%) \quad(0.41,0.82) \quad(0.41,0.84)
$$

$>2290.0$

$$
73
$$

114

0.48

0.54

$(20.3 \%)$

$$
(30.0 \%)
$$

(0.34, 0.690

$(0.37,0.80)$

Magnesium (mg)

$<117.0$

166

128

1.00

1.00

$(46.2 \%) \quad(33.7 \%)$

$117.0-220.0$

106

125

0.65

0.64

$(29.5 \%) \quad(32.9 \%) \quad(0.46,0.93) \quad(0.45,0.92)$

0.083

0.001

0.008 
$>220.0$

$$
87
$$

127

0.53

0.58

$(24.2 \%) \quad(33.4 \%) \quad(0.37,0.76) \quad(0.40,0.85)$

Calcium (mg)

0.138

$<260.0$

173

149

1.00

1.00

$(48.2 \%) \quad(39.2 \%)$

$260.0-470.0$

97

114

0.73

0.72

$(27.0 \%) \quad(30.0 \%) \quad(0.52,1.04) \quad(0.50,1.03)$

$>470.0$

89

117

0.66

0.75

$(24.8 \%)$

$(30.8 \%) \quad(0.46,0.93)$

$(0.52,1.10)$

Iron (mg)

$<6.8$

172

145

1.00

1.00

$(47.9 \%) \quad(38.2 \%)$

$6.8-13.5$

102

121

0.71

0.74

$(28.4 \%$

$(31.8 \%)$

$(0.50,1.00)$

$(0.52,1.06)$

$>13.5$

85

114

0.63

0.70

$(23.7 \%) \quad(30.0 \%) \quad(0.44,0.90) \quad(0.48,1.02)$

$\dagger$ From separate logistic regression models adjusting for age (years), gender, education level (none/primary, secondary, tertiary), body mass index (5 years ago, $\mathrm{kg} / \mathrm{m}^{2}$ ), total energy intake (kcal/day), smoking status (never, ever), alcohol drinking (never/seldom, often) and family history of cancer in first-degree relatives (no, yes). 
OR, odds ration; CI, confidence interval. 